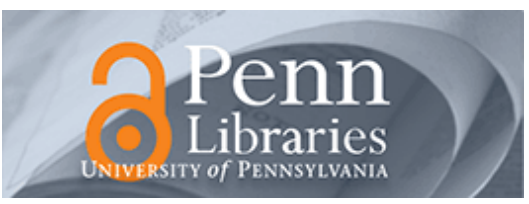

University of Pennsylvania ScholarlyCommons

November 2001

\title{
Single Wall Carbon Nanotubes Filled with Metallocenes: a First Example of Non-Fullerene Peapods
}

\author{
Ferenc Stercel \\ University of Pennsylvania, stercel@seas.upenn.edu \\ Norbert M. Nemes \\ University of Pennsylvania, nemes@sas.upenn.edu \\ John E. Fischer \\ University of Pennsylvania, fischer@seas.upenn.edu \\ David E. Luzzi \\ University of Pennsylvania, luzzi@Irsm.upenn.edu
}

Follow this and additional works at: https://repository.upenn.edu/mse_papers

\section{Recommended Citation}

Stercel, F., Nemes, N. M., Fischer, J. E., \& Luzzi, D. E. (2001). Single Wall Carbon Nanotubes Filled with Metallocenes: a First Example of Non-Fullerene Peapods. Retrieved from https://repository.upenn.edu/ mse_papers/16

Copyright Materials Research Society. Reprinted from MRS Proceedings Volume 706.

2001 Fall Meeting Symposium Z

Making Functional Materials with Nanotubes

Publisher URL: http://www.mrs.org/members/proceedings/fall2001/z/Z7_8.pdf

This paper is posted at ScholarlyCommons. https://repository.upenn.edu/mse_papers/16

For more information, please contact repository@pobox.upenn.edu. 


\title{
Single Wall Carbon Nanotubes Filled with Metallocenes: a First Example of Non- Fullerene Peapods
}

\author{
Abstract \\ We report the synthesis and analysis of metallocenes (ferrocene, chromocene, ruthenocene, vanadocene, \\ tungstenocene-dihydride) encapsulated in single wall carbon nanotubes (SWNTs). In the case of \\ ferrocene, efficient filling of the SWNTs was accomplished from both the liquid and the vapor phase. The \\ other two metallocenes were filled from the vapor phase. High resolution transmission electron \\ microscopy reveals single molecular chains of metallocenes inside SWNTs. Molecules move under the \\ electron beam in the SWNTs indicating the absence of strong chemical bonds between each other and \\ the SWNT wall. Their movement freezes after short illumination as a result of irradiation damage. Energy \\ dispersive $\mathrm{X}$-ray spectrometry confirms the presence of iron, chromium, ruthenium, vanadium and \\ tungsten.
}

\section{Comments}

Copyright Materials Research Society. Reprinted from MRS Proceedings Volume 706.

2001 Fall Meeting Symposium Z

Making Functional Materials with Nanotubes

Publisher URL: http://www.mrs.org/members/proceedings/fall2001/z/Z7_8.pdf 
Single Wall Carbon Nanotubes Filled With Metallocenes: a First Example of Non-Fullerene Peapods

\author{
F. Stercel, N. M. Nemes, J. E. Fischer, D. E. Luzzi
}

Department of Materials Science and Engineering, University of Pennsylvania Philadelphia, PA 19104-6272

\begin{abstract}
We report the synthesis and analysis of metallocenes (ferrocene, chromocene, ruthenocene, vanadocene, tungstenocene-dihydride) encapsulated in single wall carbon nanotubes (SWNTs). In the case of ferrocene, efficient filling of the SWNTs was accomplished from both the liquid and the vapor phase. The other two metallocenes were filled from the vapor phase. High resolution transmission electron microscopy reveals single molecular chains of metallocenes inside SWNTs. Molecules move under the electron beam in the SWNTs indicating the absence of strong chemical bonds between each other and the SWNT wall. Their movement freezes after short illumination as a result of irradiation damage. Energy dispersive X-ray spectrometry confirms the presence of iron, chromium, ruthenium, vanadium and tungsten.
\end{abstract}

\title{
Introduction
}

It has been shown that the lumen of SWNTs can be filled with fullerenes [1] and metallofullerenes [2-4]. Even in the weakly interacting $\mathrm{C}_{60} @$ SWNT case, SWNT properties are modified due to the encapsulated fullerene chains [5]. Stronger interactions are expected in the case of encapsulated metallofullerenes because of the charge transfer from the metal atoms to the fullerene cage. While filling with fullerenes is now well-established, a disadvantage of these systems is the difficulty in production of even scientific quantities of the metallofullerenes. In principle, similar effects on nanotube properties can be realized with other molecules that are 
more easily obtained in abundant quantities. However, until this time, no examples of nonfullerene peapods have been produced. In the present paper, we report the synthesis method and characterization of SWNTs containing chains of metallocene molecules (metallocene@SWNT).

\section{Synthesis Method and Experimental Analysis Details}

As-received carbon nanotube material produced by pulsed laser vaporization (PLV) was filtered from toluene suspension to form a mat (buckypaper). The nanotube material was purified in concentrated nitric acid and air burned at $440{ }^{\circ} \mathrm{C}$ for 20 minutes to remove amorphous carbon and to create holes in the SWNT walls. Filling reactions were carried out using several metallocenes: chromocene, ferrocene, ruthenocene and vanadocene. The thermal stability range (up to $400{ }^{\circ} \mathrm{C}$ ) and the relatively low melting point $\left(249{ }^{\circ} \mathrm{C}\right.$ ) of ferrocene allowed SWNTs to be filled with ferrocene from both the liquid and vapor phases. To accomplish liquid phase filling, solid ferrocene was added to SWNTs. The ampoule containing these materials was evacuated to $10^{-2}$ torr and sealed. The sample was then annealed at $200{ }^{\circ} \mathrm{C}$, well above the atmospheric pressure melting point of ferrocene $\left(174{ }^{\circ} \mathrm{C}\right)$ for 12 hours with the melt in contact with the nanotube buckypaper. In order to fill SWNTs with ferrocene from the vapor, a similar experiment was carried out, except that the ampoule containing ferrocene and SWNTs was heated to $250{ }^{\circ} \mathrm{C}$ - above the atmospheric pressure boiling point of ferrocene. In this case, the ferrocene was kept separated from the SWNTs within the ampoule so that the SWNTs were only in contact with the ferrocene vapor. TEM specimens were prepared by vacuum annealing the ferrocene@SWNT samples at $250{ }^{\circ} \mathrm{C}$. During this process, the excess exterior ferrocene sublimed from the nanotube material. Vanadocene, ruthenocene and chromocene SWNThybrids were prepared by filling SWNTs from the vapor phase. See Table 1 for annealing temperatures. The annealing time was 24 hours in all cases.

Table 1. Annealing temperatures for vapor phase filling of different metallocenes

\begin{tabular}{|c|c|c|c|c|c|}
\hline & Chromocene & Ferrocene & Ruthenocene & Vanadocene & $\begin{array}{c}\text { Tungstenocene } \\
\text {-dihydride }\end{array}$ \\
\hline $\begin{array}{c}\text { Annealing } \\
\text { temperature }\end{array}$ & $120^{\circ} \mathrm{C}$ & $200^{\circ} \mathrm{C}$ & $100^{\circ} \mathrm{C}$ & $120^{\circ} \mathrm{C}$ & \\
\hline
\end{tabular}


High-resolution transmission electron microscopy was carried out using a JEOL 2010F TEM with field emission gun at $100 \mathrm{kV}$ acceleration voltage in order to reduce the beam damage of the nanotubes. Energy dispersive X-ray (EDX) spectroscopy was performed to show the existence of metallocenes in the nanotube material. EDX spectra were taken from clean ropes of filled nanotubes. This ensured that the x-ray fluorescence peak corresponding to the metal in the metallocene originated from encapsulated molecules and not from metallocene molecules that might have coated parts of the specimen.

\section{Structure and Behavior of Metallocenes@SWNT}

Electron micrographs of single nanotubes show encapsulated metallocene chains as seen in Figure 1. The two dark parallel lines are the SNWT walls tangential to the electron beam and

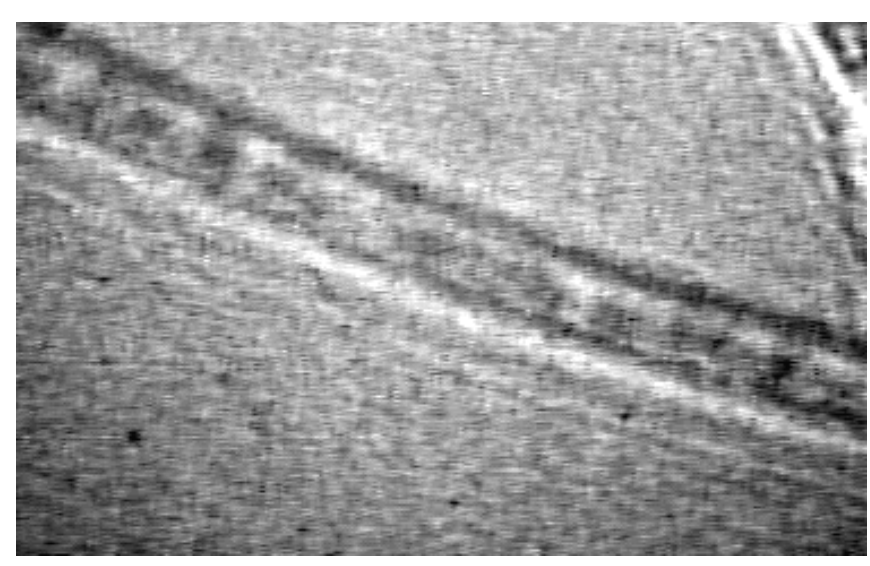

Figure 1. High-resolution electron micro-graph of a chain of ferrocene molecules encapsulated within a single-wall carbon nanotube. The dark parallel lines are the nanotube walls lying tangential to the electron beam and spaced $1.4 \mathrm{~nm}$ apart, the diameter of the nanotube. separated by approximately $1.4 \mathrm{~nm}$. The light features adjacent to the dark lines are Fresnel fringes due to the interaction of the somewhat coherent electron beam with the carbon cage of the nanotube. The chain of ferrocene molecules within the nanotube is seen as a series of dark contrast features lying between the dark lines of the nanotube walls. During observation, the metallocene molecules are seen to move within the nanotube. This movement, which is a onedimensional vibration along the tube axis, restricted by the nanotube wall, indicates that the molecules are encapsulated. The relative freedom of motion within the nanotube also indicates that the ferrocene molecules have not undergone a chemical reaction with the interior wall of the nanotube. As in the case with the fullerene encapsulates, the ferrocene molecules maintain a Van der Waals interaction with each other and with the surrounding nanotube wall. During exposure of these hybrid materials to the electron beam, the movement of the molecules 
is seen to stop after 20-40 seconds of exposure. This effect is presumably due to electron-beaminduced chemical interactions between the ferrocene molecules, and possibly between the ferrocene molecules and the surrounding nanotube walls.

EDX spectra were taken from

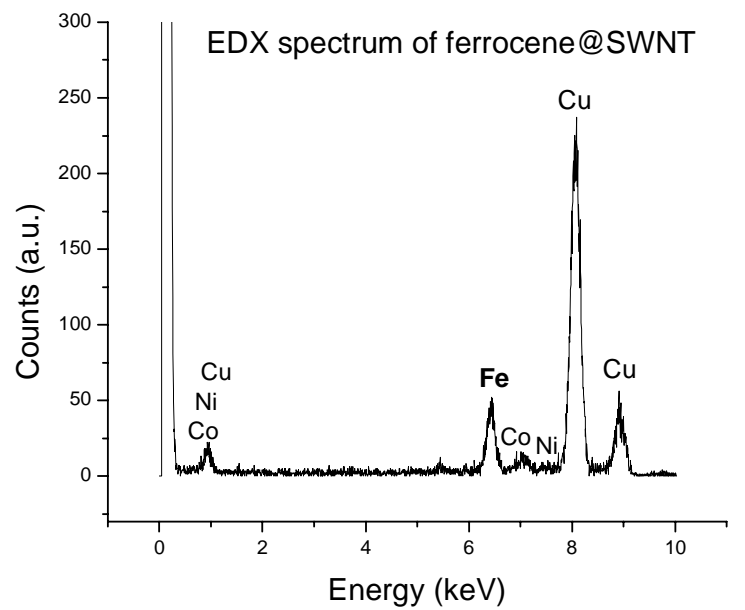

Figure 2. An energy dispersive x-ray fluorescence spectrum of a ferrocene@SWNT bundle showing a clear signature of $\mathrm{Fe}$ in the sample. The large peaks at low and high energies are due to carbon from the nanotubes and $\mathrm{Cu}$ from the sample grid. bundles of ferrocene@SWNT in order to confirm that the interior features were ferrocene molecules. During this experiment, care was taken to ensure that the bundles were not contaminated with ferrocene molecules exterior to the nanotubes. One spectrum from this data set is shown in Figure 2. In the figure, a distinct peak due to the $\mathrm{K}_{\alpha}$ fluorescence $\mathrm{X}$-rays of $\mathrm{Fe}$ can be seen at $6.398 \mathrm{keV}$. In addition, the $\mathrm{K}_{\beta}$ peak of Fe at $7.057 \mathrm{keV}$ can be seen.

The large peak at low energy is due to the $\mathrm{K}_{\alpha}$ $\mathrm{x}$-rays of carbon at $0.277 \mathrm{keV}$. The large

fluorescence peaks near 8 and $9 \mathrm{keV}$ and the smaller peak at $0.930 \mathrm{keV}$ are the $\mathrm{K}_{\alpha}, \mathrm{K}_{\beta}$ and $\mathrm{L}_{\alpha} \mathrm{X}$ ray fluorescence signature of $\mathrm{Cu}$, which is the material of the TEM sample grid. It is possible that small peaks from neighboring $3 \mathrm{~d}$ transition elements $\mathrm{Co}$ and $\mathrm{Ni}$ are present and partially overlapping the $\mathrm{Cu}$ and $\mathrm{Fe}$ peaks. $\mathrm{Co}$ and $\mathrm{Ni}$ are present within the material as residual catalyst particles from the pulsed laser vaporization process used to produce the carbon nanotubes (Tubes@Rice) used in the study. The only source of iron within the material is the ferrocene that was added during the experiment. Therefore, these EDX results confirm that SWNTs can be filled with chains of ferrocene molecules using similar synthesis procedures as that used in the earlier work on the fullerenes.

Further evidence of the general applicability of the synthesis method was developed through the production of related metallocene@SWNT hybrid materials. In Figure 3, EDX spectra are shown from hybrid materials in which SWNTs were filled with the $\mathrm{Cr}, \mathrm{Ru}, \mathrm{V}$ and $\mathrm{W}$ metallocenes by liquid-phase filling. In each case, the distinct x-ray fluorescence signature of the metal atom within the respective metallocene is detected. Similarly to the case of ferrocene 
shown in Figure 2, the spectra show strong carbon and $\mathrm{Cu}$ peaks, and weak peaks of varying intensity from residual Ni-Co catalyst. These features are common in all spectra. In order to test the origin of these other peaks, an EDX spectrum of a pure nanotube control sample material was recorded. Subtraction of the control nanotube spectrum from the experimental spectra of the metallocene@SWNT hybrids results in a single strong peak, which corresponds to the metallocene's metal characteristic X-ray peak.
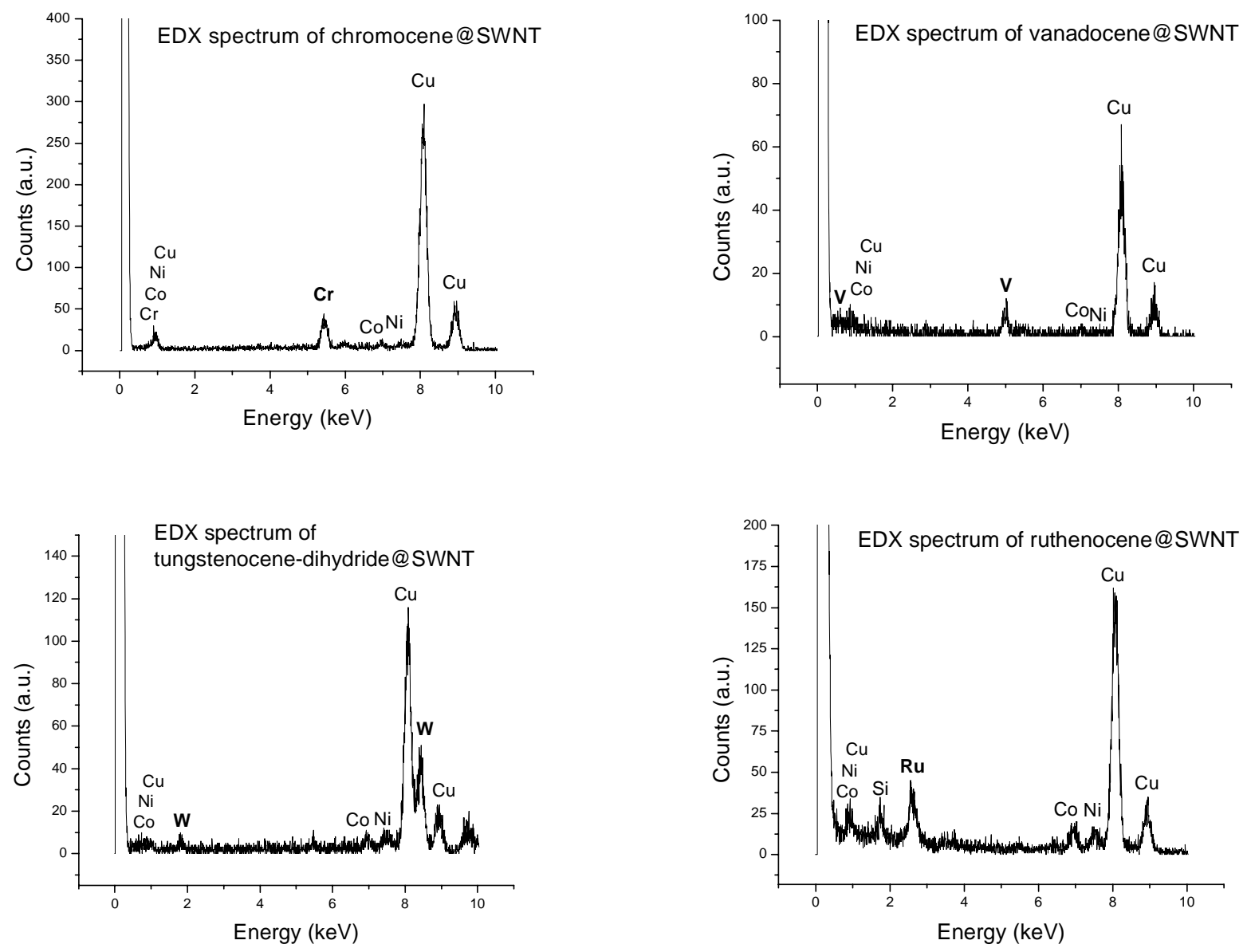

Figure 3. EDX spectra of other metallocene@SWNT hybrid 


\section{Conclusions}

Single wall carbon nanotubes (SWNTs) have been filled with different metallocene molecules in vapor phase (ferrocene, chromocene, ruthenocene, vanadocene, tungstenocenedihydride) and in liquid phase (ferrocene). High resolution electron microscopy investigations revealed chains of metallocene molecules inside SWNTs. Energy dispersive X-ray spectroscopy indicated the presence of the corresponding metal in our metallocene@SWNT samples.

\section{Acknowledgements}

The authors acknowledge financial support from the Office of Naval Research through grant \#N00014-00-1-0482 and the central facilities of the School of Engineering and Applied Science at the University of Pennsylvania partially supported through the NSF MRSEC program, grant \#DMR00-79909.

\section{References}

[1] B. W. Smith, M. Monthioux, D. E. Luzzi, Nature 396 (1998) 323.

[2] Brian W. Smith, David E. Luzzi, Yohji Achiba, Chem. Phys. Lett. 331 (2000) 137-142.

[3] K. Hirahara, K. Suenaga, S. Bandow, H. Kato, T. Okazaki, H. Shinohara, and S. Iijima, Phys. Rev. Lett. 85 (2000) 5384-5387.

[4] K. Suenaga, M. Tencé, C. Mory, C. Colliex, H. Kato, T, Okazaki, H. Shinohara, K. Hirahara, S. Bandow, S. Iijima, Science 290 (2000) 2280.

[5] D.J. Hornbaker, S.-J. Kahng, S. Misra, B.W. Smith, A.T. Johnson, E.J. Mele, D.E. Luzzi, and A. Yazdani, Science, Published online January 3, 2002; 10.1126/Science.1068133. 